Journal of Qualitative Criminal Justice \& Criminology

\title{
Book Review | Explore Everything: Place-Hacking the City
}

Kevin F. Steinmetz ${ }^{1}$

${ }^{1}$ Kansas State University

Published on: Oct 01, 2014

DOI: $10.21428 / 88 d e 04 a 1.0 d c 5085 a$

License: Creative Commons Attribution 4.0 International License (CC-BY 4.0). 
Bradley Garrett. Explore Everything: Place-Hacking the City. Verso, 2013; 273 pp.; ISBN: 9781781681299.

While most people seem content to enjoy the front-stages of everyday life-going to safe spaces deemed appropriate for occupation - there are those who are enthralled by the backstage spaces of contemporary urban landscapes. In Explore Everything: Place-Hacking the City, Bradley Garrett details his research into urban explorers, a subculture that delves into the hidden (or hidden in plain sight) city spaces such as abandoned urban ruins, underground tunnels, and imposing skyscrapers. To date, this work is most likely the definitive study of urban exploration (sometimes referred to as UE) and should be the starting point for anyone from student to academic who is interested in the situational and cultural dynamics underpinning urban exploration.

Garrett is a cultural geographer at the University of Oxford's School of Geography and the Environment. This book sprang from his doctoral thesis completed at the University of London where he spent his years deeply embedded with urban explorers. Using ethnographic methods, Garrett actively participated in numerous explorations and infiltrations, often photographically documenting his forays. In Explore Everything, Garrett pulls the reader through his (mis)adventures through wellcrafted and detailed writing in a manner both thoroughly academic yet accessible, as he transports the reader into the lived experience of urban exploration while often taking brief detours to illuminate key cultural and experiential features (and run-ins with the law) along the way.

The organization throughout Explore Everything is a mixture of chronological and thematic making for a compelling - though sometimes redundant-read. The first chapter introduces the reader to the urban exploration subculture. As he describes the general scene, establishing a foundation for the rest of the book, he immediately pulls the reader into the lived experience of urban exploration through narratives of specific expeditions into the field. Photographic images are often used throughout to reinforce the magnitude of these explorations. For instance, in the beginning of this chapter, Garrett describes ascending a crane on top of the Shard, the tallest building in London, with other urban explorers. Through photos and his visceral description, the reader can almost feel the vertigo, adrenaline rush, and sudden satisfaction of reaching the top and looking out over the busy lights of London. Also in chapter 1, Garrett introduces the features of urban exploration, the history, and his methodological approach used in this study.

Garrett continues his cultural investigation of urban exploration in chapter 2, noting how the practice is not just an exploration of space but also an exploration of time; going through various ruins, tunnels, and other forgotten spaces often bring explorers into direct confrontation with the past. Building from this theme, chapter 3 describes how spaces are always in transition, leading the reader to the notion 
that ruins, remnants of the past, are also imagined to be markers of the future. Space and time thus collapse in on themselves through urban exploration:

[T] he image of the "ruin" is emblematic not only of the fragility of capitalism but also of its inevitable destruction. Even when trespassing in construction sites, explorers love to imagine that we are seeing ghosts from a future yet to come. (p. 64)

In chapter 4, Garrett details how the London Consolidation Crew (LCC) came to be-the group with which he was primarily affiliated. He uses the formation of the group as a vehicle for detailing various subcultural group dynamics. Lyng's (1990) concept of edgework is also applied, a theme which emerges repeatedly throughout the work. Then, in chapter 5, Garrett focuses on the LCC's explorations of the London tunnel systems, highlighting how such acts are linked to the politics of resistance, a kind of reclamation of the commons which have been increasingly restricted throughout late modernity. In addition, he notes that one of the key driving motivations of urban explorers is the search for "holy grails" or the rarely explored places of the city.

Various explorations in the United States are described in chapter 6 since the LCC become fragmented after police intervention into their activities. Their expeditions included Chicago, Minneapolis, and Las Vegas. Garrett highlights unique experiences in U.S. urban exploration and further develops the UE's relationship to the contradictions and oddities of late capitalism, particularly in his descriptions of Las Vegas with its massive homeless populations, underground tunnels, and spectacles of both monetary and architectural excess.

In chapter 7, Garrett describes perhaps the most noteworthy events which took place over the course of his research, the media circus which formed around his study and the subsequent intervention of law enforcement resulting in legal trouble for himself and some of his research participants. Here we see a collision between research, deviance, transgression, and social control come together in a way that drastically affected many involved in the study.

Drawing from works in various disciplines, perhaps most heavily from cultural criminology, Garrett casts urban exploration as a politically and culturally transgressive scene in the backdrop of late modern capitalism and urbanization. He does this by highlighting the context in which urban exploration takes place as well as detailing the phenomenological experience of such transgression; in this way his work complements other noteworthy cultural criminological works such as Ferrell's (1993) investigation of graffiti writers and Hayward's (2004) descriptions of transgression in city spaces. According to Garrett, even though many urban explorers assert to be apolitical and often espouse notably libertarian views, urban exploration is often subversively political in the tradition of cultural criminology-dialectically situated as a beneficiary of late modernity and a form of resistance to it. As 
such, this book is seminal reading for any criminologist interested in ethnography and cultural criminology.

While much of this review is complementary toward Garrett's work, there are some serious criticisms to be leveled, particularly regarding research ethics. As one example, though there are others, Garrett describes finding himself (more than once) in the position of balancing his role as an active member of the urban exploration scene and his role as a researcher, particularly as he contemplated whether or not to post exploration photography and descriptions online. In both described instances, his decision was to post the material. While this earned ire from some other urban exploration groups, such seeming indiscretions, although justified through alleged subcultural demands and a desire to see his crew receive credit for first cracking these areas, eventually resulted in a media circus and his arrest of himself as well as that of other members of the urban exploration community. While Garrett attempts to justify his actions throughout, these neutralizations come off as weak, for such issues may have been easily avoided if he had erred on the side of caution (and research ethics) more often and elected to provide greater protections for his research participants.

Potential ethical issues aside, Garrett's book is a noteworthy contribution to the criminological canon and is a must read for anyone interested in cultural criminology and ethnography. The reader should be astutely aware of the ethical problems in this work, however, and perhaps use it as a cautionary tale for things to avoid in their own research endeavors. Regardless, urban exploration is an area thus neglected in criminology, and Garrett does an admirable job of making advances toward sealing this gap.

\section{References}

Ferrell, J. (1993). Crimes of style: Urban graffiti and the politics of criminality. Boston, MA: Northeastern University Press.

Hayward, K. (2004). City limits: Crime, consumer culture and the urban experience. New York, NY: Taylor \& Francis.

Lyng, S. (1990). Edgework: A social psychological analysis of voluntary risk taking. American Journal of Sociology, 95, 851-886. 